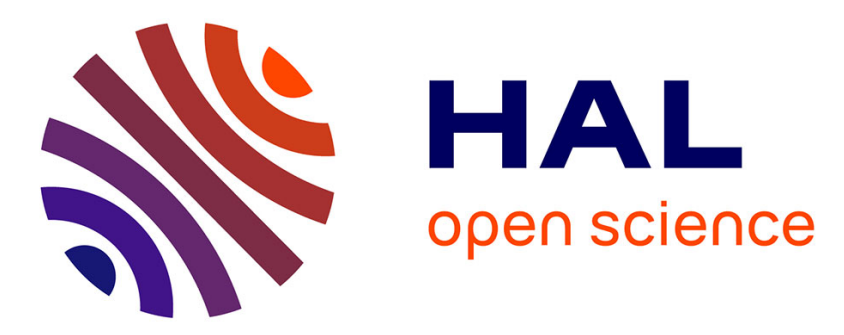

\title{
X-RAY ABSORPTION MEASUREMENTS AT THE BORON K-EDGE WITH AMORPHOUS IRON- AND NICKEL-BORON ALLOYS
}

P. Kizler, E. Hertlein, P. Vargas, S. Steeb

\section{To cite this version:}

P. Kizler, E. Hertlein, P. Vargas, S. Steeb. X-RAY ABSORPTION MEASUREMENTS AT THE BORON K-EDGE WITH AMORPHOUS IRON- AND NICKEL-BORON ALLOYS. Journal de Physique Colloques, 1986, 47 (C8), pp.C8-1019-C8-1024. 10.1051/jphyscol:19868196 . jpa-00226103

\section{HAL Id: jpa-00226103 https://hal.science/jpa-00226103}

Submitted on 1 Jan 1986

HAL is a multi-disciplinary open access archive for the deposit and dissemination of scientific research documents, whether they are published or not. The documents may come from teaching and research institutions in France or abroad, or from public or private research centers.
L'archive ouverte pluridisciplinaire HAL, est destinée au dépôt et à la diffusion de documents scientifiques de niveau recherche, publiés ou non, émanant des établissements d'enseignement et de recherche français ou étrangers, des laboratoires publics ou privés. 
JOURNAL DE PHYSIQUE

Colloque C8, supplément au $\mathrm{n}^{\circ} 12$, Tome 47, décembre 1986

X-RAY ABSORPTION MEASUREMENTS AT THE BORON K-EDGE WITH AMORPHOUS IRON- AND NICKEL-BORON ALLOYS

\author{
P. KIZLER, E. HERTLEIN, P. VARGAS* $(1)$ and S. STEEB \\ Max-Planck-Institut für Metallforschung/ \\ Werkstoffwissenschaften, seestrasse 92, D-7000 stuttgart 1 , \\ F.R.G. \\ "Max-Planck-Institut für Metallforschung/Metallphysik, \\ Heisenbergstrasse 1, D-7000 Stuttgart 80, F.R.G.
}

\begin{abstract}
X-ray absorption spectra from the k-edge of boron in amorphous and crystallized $\mathrm{Fe}_{80} \mathrm{~B}_{20}$ alloys are presented.

The spectra are discussed together with calculated densities of states, a possible core-exciton energy level and basic XANES phenomena. Satisfying coincidence between band structure calculations and experimental results can be recognized. The results in principle permit to decide between different models for the atomic structure of the amorphous $\mathrm{Fe}_{80} \mathrm{~B}_{20}$ alloy. The structure model of Zweck rather approaches the present experimental data than the model of Fujiwara.
\end{abstract}

\title{
I - INTRODUCTION
}

Among the binary amorphous alloys one of the most intensively studied one is $\mathrm{Fe}_{80^{\mathrm{B}}} 20$. Its preparation conditions, its crystallization behaviour, Itsatomic structure, its modelling, and its electronic properties have been thoroughly studied. Latest progress in performing band structure calculations to amorphous solids was applied to $\mathrm{Fe}_{80} \mathrm{~B}_{20} / 1 /$. EXAFS- and XANES-studies of the Fe-K-edge in amorphous and crystallized $\mathrm{Fe}_{80}{ }^{\mathrm{B}}{ }_{20}$ have already been published $/ 2,3,4 /$ and fulfilled their aim to give information about the vicinity of the absorbing atom, in this case the iron atom. Since there is strong interest on XAS-data of the atoms of all components present in the corresponding alloys, the present first study of boron-absorption in alloys was carried out $/ 5,6 /$.

\section{II - EXPERIMENTAL SET-UP}

The measurements have been performed at the Bexlin synchrotron radiation facility BESSY. The beamline was equipped with the plane grating monochromator SX-700 /7/, which covers an energy range from $9 \mathrm{eV}$ to $2200 \mathrm{eV}$. Its energy resolution depends from the size of the exit slit and from that area of the diffracting elements, which is exposed to the radiation $18 /$. Maximum energy resolution to be achieved at $\mathrm{E}=200 \mathrm{eV}$ is $\Delta \mathrm{E}=0.1 \mathrm{eV}$. For the present measurements, however, in most cases a tuning with $\Delta \mathrm{E}$ approximately $0.2 \mathrm{eV}$ was utilized in order to maintain higher photon flux. The absorption spectra were taken with the transmission arrangement shown in figure 1.

(1) On leave from : Physics Department USACH, Santiago-2, Chile 


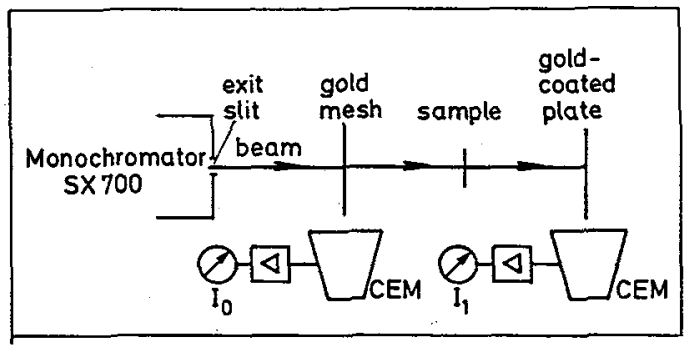

Fig.l. Experimental set-up for absorption measurements

All components were contained within an ultrahigh-vacuum system not shown in fig. 1. The incident monochromatic beam released electrons from a gold mesh, which were detected by a channel electron multiplier (CEM, type GALILEO 4700) to provide the measure for the intensity $I_{0}$ : Behind the gold mesh the beam transmitted the sample, which could be cooled to liquid nitrogen temperature. Behind the sample the beam hitted a gold-covered plate, whose electron-yield, detected by a second channeltron of the same type, yielded the signal for the intensity $I_{1}$. Thus the absorption coefficient was obtained as

$$
\mu(E)=\ln \left(I_{0} / I_{1}\right)
$$

The spectra were taken with energy steps of $0.1 \mathrm{eV}$. In spite of the high sweep rate of usually 3 seconds/energy step in many cases no splinefit was necessary during data evaluation because of the very high photon flux. For the same reason both channeltrons were operated in the current mode. Before measuring, different tests were made to verify the calibration of the instrument and to ensure that no distorsions occured in the energy range of interest.

\section{III - PREPARATION OF THE SAMPLES}

According to absorption coefficients for the energy of the B-K-edge $19,10 /$ a suitable thickness for the specimens of approximately $100 \mathrm{~nm}$ was calculated. Thin films of alloys and of boron were then prepared by RF-sputtering from molten sputter targets of the desired composition. The compounds chosen were $\mathrm{Fe} 80^{\mathrm{B}} 20^{\prime} \mathrm{Fe}_{83^{\mathrm{B}}} 7^{\prime} \mathrm{Fe}_{72} \mathrm{~B}_{28}$ and $\mathrm{Ni}_{80} \mathrm{~B}_{20}$. organic collodion film, had to serve as a carrier for the fraaile samples, which were sputtered directly onto the copper grid. After sputtering the collodion film was washed off with acetone. The specimens were proven to be amorphous by transmission electron diffraction. Crystalline samples were produced from amorphous ones by heat treatment in argon atmosphere. Crystallization heat treatment finally lets amorphous $\mathrm{Fe}_{80} \mathrm{~B}_{20}$ segregate into crystalline $\mathrm{Fe}_{2} \mathrm{~B}$ and $\alpha-\mathrm{Fe}$ but it should be noted that ${ }^{2}$ he crystallization of amorphous $\mathrm{Fe}_{80} \mathrm{~B}_{20}$ is a complex process and under certain conditions even other phases can temporarily be stable $/ 11,12,13,14 /$.

\section{IV - OVERVIEW ON THE ABSORPTION BEHAVIOUR AT THE BORON K-EDGE}

Figure 2 shows the structure of the B-K-absorption coefficient as obtained with elemental boron (upper curve). In the case of alloys fig. 2 shows the B-K-absorption coefficient after subtracting the contribution of iron or nickel. The following phenomena can be observed: - In the case of elemental boron the absorption coefficient decreases 


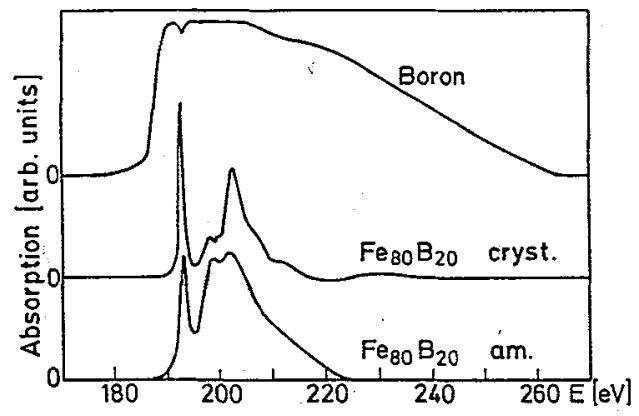

Fig.2. Boron $\mathrm{K}$-absorption in different specimers

to the background value at $260 \mathrm{eV}$, i.e. Within $80 \mathrm{eV}$, which is mach faster than known from the elements commonly studied, but similar to XAS results from other light elements like carbon or nitrogen. - In the case of the alloys the steep rise of the absorption is followed by a very steep decrease and a second absorption maximum at approximately $200 \mathrm{eV}$. In the amorphous case the absorption coefficient decreases continuously to the background, whereas in the crystalline case there are slight oscillations till $240 \mathrm{eV}$. It should be mentioned that cooling the samples to liquid nitrogen temperature does not influence the results in a significant way.

- The intense, sharp peak of half-width $0.7 \mathrm{eV}$ is located at $192.9 \mathrm{eV}$ for the crystalline sample and at $193.2 \mathrm{eV}$ for the amorphous one. Since the measurements presented in figures 2 and 3 were not taken with maximum energy resolution, the peaks appear a little broader. - Between 195 and $210 \mathrm{eV}$ the oscillations for amorphous and crystalline samples differ clearly. Peak positions are at $198.5 \mathrm{ev}$ and at $202 \mathrm{eV}$ for the amorphous sample and at 198, 200 and $202.5 \mathrm{eV}$ for the crystalline one. The restriction of the spectra to the narrow energy range between $190 \mathrm{eV}$ and $230 \mathrm{eV}$ makes conventional EXAFS data analysis impossible.

\section{$V$ - THEORETICAL CALCULATIONS, COMPARISON WITH EXPERIMENTAL DATA}

Miller et al. $/ 15,16 /$ have shown, that the $K$-edge $x$-ray absorption coefficient can be understood as a product of a matrix element $P(E)$, only weakly dependent on the energy, and the p-projected density of empty states, due to the transition rule for an initial is-state:

$$
\mu(E) \propto P(E) \cdot D O S(E)
$$

Thus the attempt was made to understand the spectra using the band structure of the alloys.

For the calculation of the DOS of $\mathrm{Fe}_{2} \mathrm{~B}$ a fully selfconsistent band structure calculation was performed, ${ }^{2}$ starting from the unit cell, which was constructed from crystallographic data $/ 17,18 /$. The calculation is based on the linear muffin-tin formalism (LMTO)/19,20/, using the atomic sphere approximation (ASA) and the local density approximation for the exchange and correlation potentials $/ 21 /$. Theoretical results for amorphous $\mathrm{Fe}-\mathrm{B}$ alloys $/ 22 /$ are based on a numerical calculation by means of continued fraction algorithms $/ 23,24 /$ using the canonical site- and distance-dependent tight-binding Hamiltonians described in $/ 25 /$. The calculations start from structural models for amorphous Fe-B alloys, set up by Fujiwara /26,27/ and Zweck $/ 28 /$. Both of them yield partial pair correlation functions, which are in good agreement with those obtained by neutron diffraction using the method of isotopic substitution $/ 29 /$.

The Fermi level in $\mathrm{Fe}_{2} \mathrm{~B}$ can be identified using the binding energy for $\mathrm{B}-1 \mathrm{~s}-\mathrm{electrons}$ in $\mathrm{Fe}_{2} \mathrm{~B}$, which was found experimentally to be $188.7 \mathrm{eV}$ 
$/ 30 /$ or $187.6 \mathrm{eV} / 31 /$. Binding energies for amorphous TM-B-alloys were not available from literature.

Using figure 3 one can compare experimental and theoretical data. Essentially three aspects have to be noticed: - good coincidence in the range from 194 to $215 \mathrm{eV}$

a)
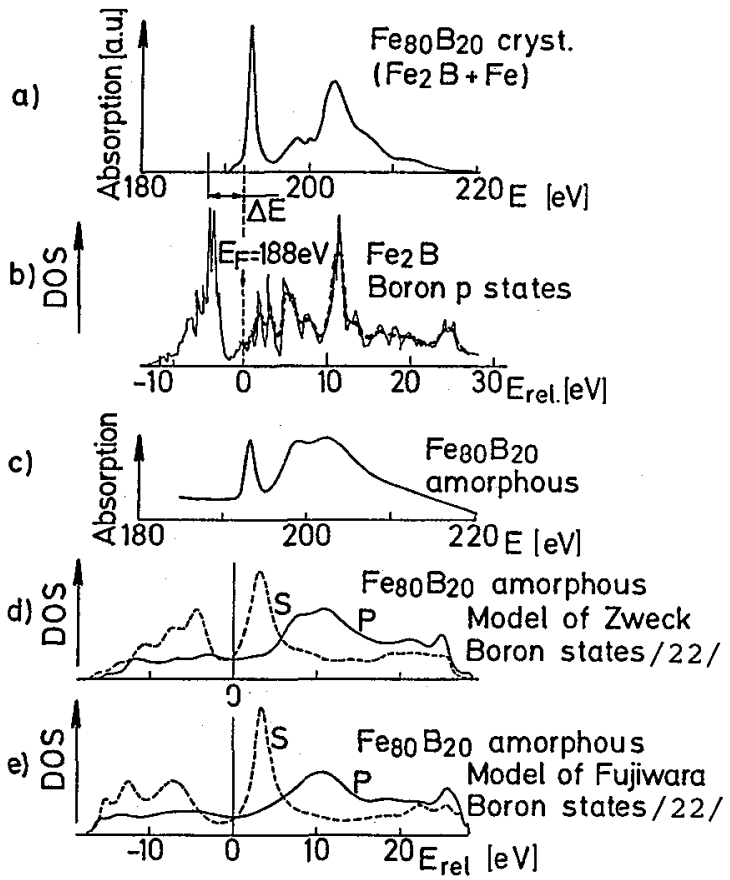

Fig.3. Boron K-edge Comparison Experiment-Theory

- non-coincidence for the peak at $193 \mathrm{eV}$

- energy shift of approximately $\Delta \mathrm{E}=4 \mathrm{eV}$ between theoretical and experimental scale.

VI - ENERGY RANGE BETWEEN

Crystalline $\mathrm{Fe}_{2} \mathrm{~B}$ :

The calculated ${ }^{2}$ DOS curve still does not involve manyparticle effects, the most important of which is the filling of the core hole and the decay of the excited state. These effects can be phenomenologically incorporated by convoluting the raw data with a Lorentzian broadening function whose width is equal to the sum of the inverse lifetimes of the core hole and the excited electron $/ 15,16 /$. The broadened curve is the dashed line in fig. $3 b$ The experimental curve for crystalline $\mathrm{Fe}_{2} \mathrm{~B}$ reflects quite well the energy positions of the maxima in the Dos curve whereas their intensities fit not so well. The question why the absorption structure vanishes above $220 \mathrm{eV}$ cannot be answered by this calculation. The answer might be found in the energy-dependence of the matrix element required for the full description of the absorption coefficient, theoretical values for this are, however, not available.

Amorphous $\mathrm{Fe}_{80} \mathrm{~B}_{20}$ :

The calculated curves for the amorphous alloy don't need to be broadened, since they are less energy-resolved. The conformity of experiment and theoretical calculations is rather obvious for the model of Zweck compared to that of Fujiwara.

VII - PEAK AT $193 \mathrm{eV}$

It has been reported that the behaviour of soft $\mathrm{X}$-ray absorption edges (in this case K-absorption edges of light elements) is very complicated and far from being completely understood. While up to this point the absorption process was regarded within an one-electron picture, for the edge region a many-body theory was developped (MND-theory), which is able to describe exciton-like energy levels in metals due to possible ineffective screening of charges /32,33/. This picture, which was already successful for explaining the Li-K-edge and the Na-L-edge, might lead to an explanation for the results obtained here. It is 
worthwile to note that similar to the present results also in $\mathrm{TiB}$ a sharp XAS-peak was observed, together with an XES-peak, located at the considerable distance of approximately $10 \mathrm{ev}$ below the absorption edge $/ 34,35 /$. This points to something similar to a band gap, also visible in $\mathrm{fig}$. $3 \mathrm{~b}$.

The multiple scattering approach, on the other hand, commonly using the computer code of Durham et al. $/ 36 /$, is also able to describe very sharp XANES-peaks /37/. In addition it can be used to predict their shifts to lower energy caused by an increasing nearest neighbour distance /38/. This shift also occurs during the crystallization of amorphous $\mathrm{Fe}_{80^{\mathrm{B}}} \mathrm{B}^{\circ}$

Regarding the band structure, the '192 ev-peak' can not be directly understood. The shape of the s-band in the DOS calculations for amorphous $\mathrm{Fe}_{8} \mathrm{~B}_{20}$ is very tempting. Transitions to this band are forbidden, but $\mathrm{ehe}^{2}$ states at this energy are not of pure s-symmetry, furthermore, they have p-parts, which must be taken into account.

It should be reminded that neither the matrix element factor from equation 2 was discussed, nor is there a complete understanding of the influence of the core-hole on the spectra $/ 39,40,41 \%$. It can be hoped that with increasing theoretical treatment the different approaches can be merged into an unique picture and that furthermore an explanation for the energy shift between the experimental and the theoretical scale can be given.

VIII - BORON K-EDGE IN OTHER TM-B-ALLOYS

The results for amorphous $\mathrm{Ni}_{80} \mathrm{~B}_{2}$ are the same as those for amorphous $\mathrm{Fe}_{80} \mathrm{~B}_{2}$. Since the boron stakes change only by a negligible amount when bound $20 \mathrm{Ni}$ instead to $\mathrm{Fe}$ it can be concluded that the boron surrounding in a-Ni $80^{\mathrm{B}} 2$ is similar to that in $\mathrm{a}-\mathrm{Fe}_{80} \mathrm{~B}_{20}$, according to results obtained by neutron diffraction $/ 42 /$.

The results for other compounds have shown the great sensibility of the $\mathrm{B}-\mathrm{K}$-edge for distinct structures and phase segregation.

IX - CONCLUSIONS

$\mathrm{X}$-ray absorption measurements of the $\mathrm{B}-\mathrm{K}$-edge with different iron- and nickel-boron alloys are presented. The spectra of amorphous $\mathrm{Fe}_{80} \mathrm{~B}_{20}$ and crystalline $\mathrm{Fe}_{2} \mathrm{~B}$ are discussed in detail. For the low energy parts. of the spectra analogies to similar physical observations are given. The high energy parts agree well with DOS-calculations which were done by Fembacher et al. for two different structural models of amorphous $\mathrm{Fe}_{80^{\mathrm{B}}} 20^{\circ}$

\section{ACKNOWLEDGEMENTS}

Thanks are due to H. Petersen (BESSY Berlin) and A. Puschmann (FHI Berlin), whose technical assistance during the measurements was an indispensable help. Futhermore we would like to thank N.E. Christensen (MPI/Festkörperforschung, Stuttgart) for advise during the band structure calculations for crystalline. $\mathrm{Fe}_{2} \mathrm{~B}$ and $\mathrm{L}$. Ley (MPI/Festkörperforschung, stuttgart) for valuable discussions.

\section{REFERENCES}

1) T. Fujiwara, J. non-cryst. solids, 61\&62, 1039 (1984)

2) R. Haensel, R. Rabe, G. Tolkiehn, A. Werner in: Liquid and Amorphous Alloys, eds. E. Lúscher and H. Coufal, Proc. of the NATO Adv. Study Inst. (Sijthoff and Noordhoff International Publishers B.V. Aiphen aan den Rijn, The Netherlands, 1980) 
3) M. De Crescenzi et al., Sol. Stat. Comm. 37, 921 (1981)

4) F. Schmückle, P. Lamparter, S. Steeb,

z. Naturforschung $37 a, 572$ (1982)

5) E. Hertlein, diploma thesis, Universität Stuttgart, (1985)

6) E. Hertlein, P. Kizler, P. Lamparter, S. Steeb, BESSY annual report 1985

7) H. Petersen, H. Baumgärtel, Nucl. Instr. \& Meth.172, 191 (1980)

8) H. Petersen, Technischer Bericht BESSY TB 29 (19 $\overline{80}$ )

9) W. Weisweiler, Mikrochimica Acta 744 (1970)

10) E. Bertin, Principles and Practice of X-Ray Spectrometric Analysis Plenum Press, New York (1970)

11) U. Herold, U. Köster, Z. Metallkunde 69, 326 (1978)

12) Y. Khan, M. Sostarich, Z. Metallkunde $\frac{72}{72}, 266$ (1981)

13) Y. Khan, E. Kneller, M. Sostarich, Z. Metallkunde 72, 553 (1981)

14) F. Stobiecki, S. Schwarzl, T. Stobiecki, H. Hoffmann, $\mathrm{J}$. de physique, Collogue $\mathrm{C} 8, \mathrm{C} 8-171$ (1980)

15) J.E. Müller et al. , Sol. Stat. Comm. 42, 365 (1982)

16) J.E. Müller, J.W. Wilkins, Phys. Rev. B29, 4331 (1984)

17) W.B. Pearson, Handbook of Lattice Spacings and Structures of Metals and Alloys Pergamon Press, Oxford (1967)

18) K. Schubert, Kristallstrukturen zweikomponentiger Phasen Springer, Berlin (1964)

19) O.K. Andersen, Phys. Rev. B12, 3060 (1975)

20) H.L. Skriver in: 'the LMTO-Method', Springer series in Solid-State Sciences 41, ed. by $M$. Cardona et al.; Springer, Berlin (1984)

21) U. Barth, L. Hedin, J. Phys. C5, 1629 (1972)

22) W. Fembacher, U. Krey, H. Ostermeier, Proceedings of the LAM6 Conference, Garmisch-Partenkirchen, (1986) to be published in $z$. $f$. physikalische Chemie

23) W. Fembacher, Thesis, Universität Regensburg (1985)

24) J. Stein, U. Krey, Z. Physik B37, 13 (1980)

25) W. Harrison, Electronic Structure and the Properties of Solids Freeman \& Co, San Francisco (1980)

26) T. Fujiwara, H.S. Chen, Y. Waseda, J. Phys. F12, 251 (1982)

2.7) T. Fujiwara, H.S. Chen, Y. Waseda, Z. Naturforsch. 37a, 611 (1982)

28) J. Zweck, Thesis, Universität Regensburg (1986) (in preparation)

29) E. Nold, P. Lamparter, H. Olbrich, G. Rainer-Harbach, S. Steeb, Z. Naturforschung 36a, 1032 (1981)

30) V.G. Aleshin et al., Phys. Stat. Sol. (b) 83, 537 (1977)

31) G. Mavel et al., Surface Science 35, 109 (1973)

32) D.W. Lynch, in: Synchrontron Radiation, ed. by C. Kunz, Topics in Current Physics 10, Springer, Berlin (1979), p. 376

33) C. Kunz, in: Optical Properties of Solids, edited by B.o. Seraphin, North-Holland Publishing, Amsterdam (1976) p. 477

34) L.P. Mokhravecha, P.V. Gel'd, Izvestiya Akademii Nauk SSSR, Neorganicheskie Materialy, 20, 949 (1984)

35) D. Jehnichen et al. in: Proc. 13th Int. Symp. on Electronic Structure of Metals and.Alloys, 2.-6. May 1983, Johnsbach/G.D.R.

36) P.J. Durham et al., Comp. Phys. Comm. 25, 193 (1982)

37) T. Lindner, H. Sauer, W. Engel, K. Kambe, Phys. Rev. B33, 22 (1986)

38) A. Bianconi et a1., Phys. Rev. B26, 6502 (1982)

39) B. Lengeler, R. Zeiler, Sol. Stat. Comm. 51, 889 (1984)

40) I.A. Grunes, Phys. Rev. B27, 2111 (1983)

41) G. Materlik et al., Phys. Rev. Lett. 50, 267, (1983)

42) P. Lamparter, W. Sperl, G. Rainer-Harbach, S. Steeb, z. Naturforschung $36 a, 419$ (1981) 